Continuing education

\title{
Low lactose in the nutritional management of diarrhea: Case reports from India
}

\author{
Gaurav Sethi ${ }^{\mathrm{a}}$, Srinivas Sankaranarayanan ${ }^{\mathrm{b}}$, Manpreet Sukhija ${ }^{\mathrm{c}, *}$ \\ a In Good Hands Specialist Child Care, D-95, Ajay Enclave, New Delhi, 110018, India \\ b Apollo Children's hospital, 15 Shafee Mohammed road, Thousand lights, Chennai, India \\ ${ }^{\mathrm{c}}$ Nestle Nutrition, Nestlé House, Jacaranda Marg, DLF Phase 2, Gurgaon 122002, India
}

\section{A R T I C L E I N F O}

\section{Keywords:}

Low Lactose

Diarrhea

Infants

\begin{abstract}
A B S T R A C T
Diarrhea is the second leading cause of death in under-5 children. In addition to usual care, lactose avoidance is advised by physicians to manage diarrhea in children. Lactose is vital for growth and development in children. There is paucity of data from India on use of low lactose diet in infants with diarrhea. This article presents case reports from India for four infants with diarrhea managed with low-lactose formulas to maintain energy and nutrient intakes without avoiding lactose entirely.
\end{abstract}

\section{Introduction}

Globally, diarrhea is the second leading cause of death in children under 5 years of age that kills nearly 525000 children every year. ${ }^{1}$ In India, slightly over $9 \%$ of children under 5 years had diarrhea in the last 2 weeks preceding the recent National Family Health Survey-4 (NFHS4 ; 2015-16) with a slightly higher prevalence in rural areas compared to the urban areas. ${ }^{2}$ The Global Enteric Multicenter Study, a prospective case-control study conducted in sub-Saharan Africa and south Asia reported that a child under 5 years of age with a single episode of moderate or severe diarrhea is 8.5 times more likely to die from diarrhea compared to age-, sex- and residence-matched controls with no diarrhea in the past 7 days at enrolment. ${ }^{3}$ Although the burden of childhood deaths from diarrhea is alarmingly high, there has been a progress from 2000 to 2015 . The annual under-5 childhood deaths from diarrhea reduced by more than $50 \%$ suggesting that many lives could be saved by following basic interventions. ${ }^{1}$ The current recommendations by the WHO and the UNICEF advocate continued feeding along with oral rehydration solution (ORS) and zinc supplementation in the management of diarrhea. ${ }^{4}$ One of the other important findings from the Global Enteric Multicenter Study was that the linear growth vacillated significantly in the 2 months following the diarrheal episode in children with moderate to severe diarrhea, due to the associated nutritionally compromised state. ${ }^{3}$ This reiterates the fact that nutritional management should be an important part of the algorithm to manage diarrhea. The optimal diet in the management of diarrhea apart from continued breastfeeding is a matter of ongoing debate. ${ }^{5}$ Lactose malabsorption is one of the common problems encountered in children with diarrhea which occurs as a result of secondary deficiency of lactase (the enzyme that helps in the absorption of lactose) during diarrhea. Continued administration of lactose-containing diets in children who are unable to absorb lactose may lead to the development of osmotic diarrhea. This is one of the primary reasons for avoiding lactose in children with diarrhea. However, the importance of lactose in infant growth and development is often underrecognized. ${ }^{6}$ Thus, use of low lactose diets in children with diarrhea may be one the methods to strike a balance between the benefits and adverse effects of lactose. This paper describes some cases where positive outcomes were observed with low lactose formulas in the diets of infants presenting with diarrhea.

\section{Case report}

\subsection{Case 1}

A 3-week old, exclusively breastfed infant presented with increased frequency of stools since birth. During the first week of life, a diagnosis of transitional stools was made by the treating pediatrician and the mother was reassured. However, diarrhea persisted even after two weeks. The stools were watery, yellow and occasionally green, and occurred after every feed. The mother described the stools as frothy that often passed forcefully after audible intestinal peristalsis.

The infant's birth weight was $3.2 \mathrm{~kg}$ and the infant had gained acceptable weight over the past 3 weeks. Examination revealed severe perianal redness and erythema around the skin of the anus. The infant was irritable due to excessive stooling and perianal inflammation. He was breastfed typically about $7-8 \mathrm{~min}$ at each breast and the further

\footnotetext{
* Corresponding author

E-mail addresses: ingoodhands.gaurav@gmail.com (G. Sethi), dr.srinis@gmail.com (S. Sankaranarayanan), Manpreet.Sukhija@in.nestle.com (M. Sukhija).
} 
questioning revealed that the breastmilk was relatively thin and watery.

A clinical diagnosis of foremilk diarrhea causing lactose intolerance was made and the mother was advised to avoid foremilk and feed only the hindmilk preferentially. Breastfeeding was supervised with special attention to the technique of latching and attachment although no problems were detected. The infant was assessed again after a week; there was mild improvement in perianal erythema and the infant's appetite had increased than before associated with crying for feeds quite often. At the end of one month, the infant's weight was $3.75 \mathrm{~kg}$. In view of suboptimal weight gain and severe perianal erythema (due to high lactose content of the watery foremilk); he was started on supplemental low-lactose formula. The infant was also advised oral lactase enzyme supplementation as drops along with every breastfeed and topical analgesic creams to treat the perianal excoriation.

Initially, the infant was fed breastmilk and low-lactose formulas alternately. The mother was counselled on the importance of continuing breastfeeding and reassured. She was counselled on the importance of consuming whole-some nutritious diet rich in natural galactagogues. The infant was assessed every 7 days. Frequency of loose stools and perianal excoriation decreased significantly with an improvement in weight gain. At 1.5 months during the first immunization visit, the infant's weight was $4.25 \mathrm{~kg}$. The mother also reported gradual decrease in foremilk and increased hindmilk content while feeding. The ratio of breastfeed to formula feed was reduced from 1:1 to $1: 2$ and then further to 1:3 after another 2 weeks.

At 2.5 months, the infant weighed $5.25 \mathrm{~kg}$ and reported no perianal erythema. The infant was passing formed stools and still needed 1-2 supplemental feeds during the day. The infant was switched to standard infant formula instead of low-lactose formula to meet the needs. Regular follow-up showed satisfactory weight gain without diarrhea and the infant continued to be on breastfeeds as well as supplemental infant formula. This occasional need of supplemental standard formula (once or twice a day) was eventually replaced by weaning the child onto rice cereal at 5 months of age.

\subsection{Case 2}

An 8-month-old boy presented with a history of increased stool frequency over the past 3-4 days. The infant was reported to have had at least 11-12 watery, green stools per day. There was no history of vomiting or other associated symptoms. His past medical history was nonsignificant, and he weighed $11 \mathrm{~kg}$ at presentation. He was fed formula milk with a bottle and was recently started on cow's milk. His systemic examination was normal, and he showed no signs of dehydration.

The infant was diagnosed as having acute watery diarrhea. His parents were advised to increase his fluid intake, feed him oral rehydration solution after every stool, administer zinc supplements in the form of drops (for 14 days). He was prescribed antipyretics for fever (if present). In addition, probiotics were advised for 7 days. The parents were advised to feed the infant with small, frequent meals and preferably soft and bland food such as curd, banana, or rice and pulses gruel. They were also advised to replace the current formula with a low lactose formula starting from the day of presentation (7 scoops 3 to 4 times a day) for 15 days.

On the first follow-up after 6 days, the infant was passing 5-7 stools per day and weighed $11.02 \mathrm{~kg}$. The infant was taking low lactose formula ( 8 to 10 feeds per day of $90-120 \mathrm{~mL}$ each) along with soft, bland semi-solid foods. He had cold and runny nose for which he was prescribed an antihistaminic. The parents reported an improvement in the infant's appetite. During the second follow-up after 2 weeks of initial presentation, his stool frequency had reduced to 2-3 episodes per day. the infant weighed $11.1 \mathrm{~kg}$, showed normal activity, and reported improved appetite although his appetite was still less than normal. There was an overall improvement in the infant's well-being.
Table 1

Results of laboratory investigations.

\begin{tabular}{ll}
\hline Parameters & Results \\
\hline Hemoglobin & $11.2 \mathrm{~g} / \mathrm{dL}$ \\
Total count & 11,000 cells $/ \mathrm{mm}^{3}$ \\
Differential count & Polymorphs: 45 \\
& Lymphocytes: 55 \\
Platelet count & 2.65 lakhs $/ \mu \mathrm{L}$ \\
Blood urea nitrogen & $45 \mathrm{mg} / \mathrm{dL}$ \\
Serum creatinine & $1.1 \mathrm{mg} / \mathrm{dL}$ \\
Sodium & $133 \mathrm{mEq} / \mathrm{L}$ \\
Potassium & $2.8 \mathrm{mEq} / \mathrm{L}$ \\
Bicarbonates & $16 \mathrm{mEq} / \mathrm{L}$ \\
Stool rotavirus antigen & Positive \\
\hline
\end{tabular}

\subsection{Case 3}

A 6-month-old infant weighing $6 \mathrm{~kg}$ presented with acute watery diarrhea of 4 days duration. The infant also had vomiting leading to dehydration and warranting the need for intravenous fluid replacement. The infant's medical history was non-significant and he was on formula feeds. Physical examination was essentially normal. Laboratory investigations revealed azotemia, mild dyselectrolytemia and mild metabolic acidosis (Table 1).

The infant was admitted immediately and dehydration, azotemia and dyselectrolytemia were corrected promptly. After rehydration, the infant's weight was $6.5 \mathrm{~kg}$. Zinc supplements were advised. However, the infant had recurrent dehydration while on standard formula and developed perianal excoriation due to ongoing diarrhea and lactose intolerance during the next 2 days.

The parents were advised to use soy-based formula instead of standard formula. The parents reported that the infant disliked the taste of the new formula which often resulted in vomiting most of the formula consumed. The infant was subsequently switched to a low-lactose formula on day 7 of the illness. The child was also given rice cereal and porridge. The infant continued to have loose stools during the hospitalisation for another 3 days although there were no signs of dehydration. At discharge, perianal excoriation had decreased and there was a good weight gain $(6.6 \mathrm{~kg})$. The child was continued on a low lactose formula for another 2 weeks with excellent weight gain $(6.9 \mathrm{~kg})$ and was subsequently able to tolerate standard formula.

\subsection{Case 4}

A 11-month-old girl presented with complaints of watery stools (7-8 episodes/day) and vomiting for the past 2 days. The infant had received 4 doses of ofloxacin over the past 2 days, to which she did not respond. Her parents reported she had mild cold. Her appetite was reduced and she was irritable. The infant had reached normal developmental milestones for her age with no significant medical history. She was fed infant's formula along with complementary foods.

On physical examination, the infant showed no signs of dehydration, her chest was clear and abdomen was soft on palpation. She weighed $9.3 \mathrm{~kg}$ at presentation. A provisional diagnosis of acute watery diarrhea was made and the infant was immediately initiated on oral rehydration salts, zinc supplementation and probiotics twice daily for 7 days. The parents were advised to feed the infant with low-lactose formula (7 scoops per feed 3 to 4 times a day) instead of the regular formula for 15 days. They were also advised to feed soft and bland diet and include more of liquids such as lemonade, butter milk and coconut water. At the follow-up visit on day 5, the parents reported that the frequency of watery stools had diminished to 5-6 episodes per day and the stool consistency was better. Although, the infant was active, her appetite was still subnormal. She was consuming low lactose formula (100 mL 3 times a day) instead of the regular formula along with a soft, bland diet. She weighed $9.48 \mathrm{~kg}$ during the first follow-up visit. The 
parents were advised to feed her a healthy and balanced diet. At the second follow-up visit on day 8, there was an improvement in the infant's appetite and activity and she was passing formed stools 4-5 times a day. At the third follow-up on day 15, the infant was feeling better with a good appetite and activity. She weighed $9.5 \mathrm{~kg}$ and had a stool frequency of 4 to 5 per day.

\section{Discussion}

Lactose avoidance is one of the strategies that has gained importance over the time in diarrhea management. Due to the risk of worsening diarrhea and development of secondary lactose intolerance, lactose is often eliminated from the diets of children with diarrhea. ${ }^{7}$ The lactase enzyme that breaks down lactose is present at the tips of the intestinal villi which makes it extremely vulnerable to intestinal injury and disorders. Disruption of the intestinal barrier during diarrhea often predisposes the infant to lactose intolerance temporarily because of the loss of epithelial cells that contain lactase. ${ }^{6}$ The osmotic effects of undigested lactose draw fluid into the intestinal lumen causing loose stools. ${ }^{8}$ However, secondary lactose intolerance generally does not last longer than 6-8 weeks ${ }^{9}$ and lactase activity may return to normal after the repair of intestinal damage. ${ }^{10}$

Breastfed infants receive more than $40 \%$ of the energy from lactose. ${ }^{11}$ It is also the most abundant carbohydrate in mammalian milk, and human milk contains nearly $6.7-7.8 \mathrm{~g} / \mathrm{dL}$ of lactose, the highest among the milk of other animals. ${ }^{7,11,12}$ Besides its role as an energy source, lactose plays a crucial role in the growth and development of infants. It is the only source of galactose that plays a major role in myelination. ${ }^{13}$ Furthermore, lactose has been shown to support the absorption of various minerals including calcium, copper and manganese $\mathrm{e}^{14,15}$ and has a prebiotic effect on the gut microbiota. ${ }^{16}$

Though it seems common practice to avoid lactose in acute diarrhea, it is debatable whether restricting lactose intake completely in infants during vital phase of growth and development is appropriate. The European Society of Paediatric Gastroenterology, Hepatology and Nutrition (ESPGHAN) guidelines currently do not recommend the routine use of lactose-free feeds in outpatient setting for children with acute gastroenteritis. However, lactose restriction is recommended in children with persistent diarrhea. ${ }^{17}$ Both WHO and the Indian Academy of Pediatrics emphasizes the use of low-lactose diets in the nutritional management of persistent diarrhea. ${ }^{18,19}$ Thus, it may be a good choice to use a low-lactose formula instead of eliminating lactose completely in the management of acute or persistent diarrhea with secondary lactose intolerance.

In the aforementioned case reports, infants with diarrhea were managed with low-lactose formulas instead of regular formulas to help maintain energy and nutrient intakes. Human milk remains the best food for the babies. It is usual practice not to withhold breastmilk even if the symptoms are suggestive of lactose intolerance. In case of breastfed infants, it is important for the mother to understand that her breast milk is the best food for the baby in long-term. However, in infants who are not breastfed and have inadequate weight gain, lowlactose formulas may be beneficial. Published literature suggests that low-lactose formulas improve early weight gain in infants with acute diarrhea. ${ }^{20,21}$ In a randomized controlled trial involving 135 children older than 2 years, low-lactose formula caused a significant early weight gain (within $48 \mathrm{~h}$ ) compared with a lactose-free corn syrup-based formula. ${ }^{20}$ In a prospective, randomized trial, 60 children of (median age: 130 days) with acute enteritis were randomized to receive either a standard infant formula diluted with water or a low- lactose formula. The low-lactose group was associated with a steady increase in weight from the first day with a significantly higher weight gain observed over the first 5 days, compared with the standard diluted infant formula group. ${ }^{21}$ Low-lactose, low-fat formula was found to hasten recovery in infants with gastroenteritis in the initial post rehydration phase compared with conventional formula and hydrolyzed soya and collagen feeds. ${ }^{22}$

Thus, low lactose formulas can play an important role in effective management of diarrhea. In India, while prevalence of diarrhea is high, there is limited evidence on the effects of low-lactose in the management of diarrhea. These case reports add to existing evidence on low lactose formulas in acute diarrhea. Further research can be done to build on this evidence in the Indian population.

\section{Conflict of interest}

The authors have none to declare.

The support for this manuscript is from Nestle Nutrition Institute, South Asia. Author MS is employee of Nestle nutrition.

\section{Acknowledgements} vices.

We would like to thank BioQuest Solutions for their editorial ser-

\section{References}

[1]. UNICEF. Diarrhoeal disease factsheet. Available at https://data.unicef.org/topic/ child-health/diarrhoeal-disease/\#. Accessed 24 May 2017.

[2]. National Family Health Survey (NFHS-4) 2015-16. Available at http://rchiips.org/ NFHS/pdf/NFHS4/India.pdf. Accessed 24 May 2017.

[3]. Kotloff KL, Nataro JP, Blackwelder WC, Nasrin D, Farag TH, Panchalingam S, et al. Burden and aetiology of diarrhoeal disease in infants and young children in developing countries (the Global Enteric Multicenter Study, GEMS): A prospective, case-control study. Lancet. 2013;382:209-222.

[4]. UNICEF/WHO. Diarrhoea: why children are still dying and what can be done. New York and Geneva: United Nations Children's Fund and the World Health Organization; 2009. p. 58.

[5]. Gaffey MF, Wazney K, Bassani DG, Bhutta Zulfiqar A. Dietary management of childhood diarrhea in low- and middle-income countries: a systematic review. BMC Public Health. 2013;13(3):S17.

[6]. Grenov V. Undernourished children and milk lactose. Food Nutr Bull. 2016;37:85-99.

[7]. MacGillivray S, Fahey T, McGuire W. Lactose avoidance for young children with acute diarrhea. Cochrane Database Syst Rev. 2013(10):CD005433http://dx.doi.org/ 10.1002/14651858.CD005433.pub2.

[8]. Heyman MB. Lactose intolerance in infants, children, and adolescents. Pediatrics. 2006;118:1279.

[9]. Prescribing Guidelines of Infant Formula for Infants with Cow's Milk Protein Allergy (CMPA) or Lactose Intolerance. Available at http://www.neneccg.nhs.uk/ resources/uploads/files/Infant\%20Formula\%20Prescribing\%20Guidelines.pdf. Accessed 24 May 2017.

[10]. Szajewska H, Shamir R, eds. Evidence-based research in pediatric nutrition. World Review of Nutrition and Dietetics. Vol. 108. 2013: Karger Publications; 2018.

[11]. Ballard O, Morrow AL. Human milk composition: Nutrients and bioactive factors. Pediatr Clin North Am. 2013:60:49-74.

[12]. Schaafsma G. Lactose and lactose derivatives as bioactive ingredients in human nutrition. Int Dairy J. 2008;18:458-465.

[13]. Rowland D, ed. Nutritional solutions for 88 conditions: Correct the causes. 2017: DW Rowland Enterprises Inc; 2018.

[14]. Ziegler E, Foment S. Lactose enhances mineral absorption in infancy. J Pediatr Gastroenterol Nutr. 1983;2:288-294.

[15]. Abrams S, Griffin I, Davila P. Calcium and zinc absorption from lactose-containing and lactose free infant formulas. Am J Clin Nutr. 2002;76:442-446.

[16]. Francavilla R, Calasso M, Calace L, Siragusa S, Ndagijimana M, Vernocchi P, et al. Effect of lactose on gut microbiota and metabolome of infants with cow's milk allergy. Pediatr Allergy Immunol. 2012;23:420-427.

[17]. Guarino A, Ashkenazi S, Gendrel D, Lo Vecchio A, Shamir R, Szajewska H, et al. European Society for Paediatric Gastroenterology, Hepatology, and Nutrition/ European Society for Paediatric Infectious Diseases Evidence-based guidelines for the management of acute gastroenteritis in children in Europe: Update 2014. J Pediatr Gastroenterol Nutr. 2014;59:132-152.

[18]. Pocket book of hospital care for children: Guidelines for the management of common childhood illnesses. Diarrhoea. 2nd edn Switzerland: World Health Organization; 2013:125-146.

[19]. Bhatnagar S, Lodha R, Choudhary P, Sachdev HP, Shah N, Narayan S, et al. IAP Guidelines 2006 on hospital based management of severely malnourished children (Adapted from the WHO Guidelines). Indian Paediatrics. 2007;44:443-461.

[20]. Wall CR, Webster J, Quirk P, Robb TA, Cleghorn GJ, Davidson GP, et al. The nutritional management of acute diarrhea in young infants: effect of carbohydrate ingested. J Pediatr Gastroenterol Nutr. 1994;19:170-174.

[21]. Woweries J, Dressler F. Re-feeding infants with acute enteritis with a hydrolyzed infant formula. Pädiatr Grenzgeb. 1997;36:137-144.

[22]. McClean P, Lynch AB, Dodge JA. Comparison of three regimens in the management of acute gastroenteritis in infants. Aliment Pharmacol Ther. 1990;4:457-464. 